Tropical Journal of Pharmaceutical Research September 2015; 14 (9): 1673-1678

ISSN: $1596-5996$ (print); 1596-9827 (electronic)

(C) Pharmacotherapy Group, Faculty of Pharmacy, University of Benin, Benin City, 300001 Nigeria.

All rights reserved.

Available online at http://www.tjpr.org

Original Research Article

http://dx.doi.org/10.4314/tjpr.v14i9.18

\title{
Gas Chromatography-Mass Spectrometric Analysis of Nematicidal Essential Oil of Valeriana amurensis P Smirn ex Kom (Valerianaceae) Roots and its Activity against Heterodera avenae
}

\author{
Yun Chao Li, Hua Ji and Hong Tao $\mathrm{Li}^{\star}$ \\ Institute of Genetics and Physiology, Hebei Academy of Agricultural and Forestry Sciences, Shijiazhuang 050051, PR China \\ ${ }^{*}$ For correspondence: Email: lihongtao1314@hotmail.com; Tel: +86-311-13933107622; Fax: +86-311-87652319 \\ Received: 25 March 2015 \\ Revised accepted: 25 July 2015
}

\begin{abstract}
Purpose: To investigate the chemical composition and nematicidal activity of the essential oil of Valeriana amurensis roots against cereal cyst nematodes (Heterodera avenae).

Methods: The essential oil of $V$. amurensis roots was obtained by hydrodistillation and analyzed by gas chromatography (GC) and gas chromaotography-mass spectrometry (GC-MS). The nematicidal activity of the essential oil and its major constituents was determined against second stage juveniles of $H$. avenae.

Results: A total of 33 components of the essential oil were identified. The major constituents were bornyl acetate (12.5\%), patchoulol (11.6\%), caryophyllene (8.2\%), 3-methylvaleric acid (7.3 \%) and isovaleric acid $(6.5 \%)$. The essential oil exhibited nematicidal activity against $H$. avenae with a medium lethal concentration ( $L C_{50}$ ) value of $311.6 \mu \mathrm{g} / \mathrm{mL}$. The major constituents, isovaleric acid and 3methylvaleric acid, exhibited nematicidal activity against $H$. avenae with $L C_{50}$ of 218.2 and $683.8 \mu \mathrm{g} / \mathrm{mL}$, respectively.

Conclusion: The study indicates that the essential oil of $V$. amurensis roots and its two major constituents, isovaleric acid and 3-methylvaleric acid, have a potential to be developed to natural nematicides for the control of cereal cyst nematodes.
\end{abstract}

Keywords: Valeriana amurensis, Heterodera avenae, Nematicidal activity, Isovaleric acid, 3Methylvaleric acid, Essential oil, Cereal cyst nematodes

Tropical Journal of Pharmaceutical Research is indexed by Science Citation Index (SciSearch), Scopus, International Pharmaceutical Abstract, Chemical Abstracts, Embase, Index Copernicus, EBSCO, African Index Medicus, JournalSeek, Journal Citation Reports/Science Edition, Directory of Open Access Journals (DOAJ), African Journal Online, Bioline International, Open-J-Gate and Pharmacy Abstracts

\section{INTRODUCTION}

During the screening program for new agrochemicals from Chinese medicinal herbs and wild plants, the essential oil of Valeriana amurensis P. Smirn. ex Kom. roots was found to possess nematicidal activity against cereal cyst nematodes (Heterodera avenae Wollenweber). Nematode management is generally based upon chemical treatments, but environmental concerns and governmental regulations are now resulting in a strong interest in nematicides of natural origin [1] Many plant constituents and metabolites including essential oils have been investigated for activity against plant - parasitic nematodes [2-7]. The results suggest that some of the essential oils tested and selected constituents are potential natural pesticides in the control of nematodes.

The genus Valeriana belongs to the family Valerianaceae and is distributed in Asia, Europe, 
North and South America with about 300 species in the world, of which 21 species (13 endemic) are distributed in China [8]. $V$. amurensis is a perennial herb $(80-150 \mathrm{~cm}$ tall) and grows in hillside meadows, larch and birch forest in Heilongjiang and Jilin provinces in China as well as Korea, Russia (Far East) [8].

The roots and rhizomes of this plant are widely used in phytotherapy for the preparation of phytomedicines with sedative, antispasmodic, carminative, mild anodyne and hypotensive properties [9-11]. This herb has also been used to treat dementia in Mongolian preparations for a long time [12]. From the roots and rhizomes of $V$. amurensis, iridoid glycosides, monoterpeneglucosides, phenylpropanoids glycosides, sesquiterpenoids, triterpenoids, lignans and phenolic acids have been isolated [9-14]. The chemical composition of the essential oils derived from $V$. amurensis has also been determined [15-18]. However, a literature survey shows that there is no report on nematicidal activity of the essential oil derived from $V$. amurensis roots. Thus, the objective of this study was to investigate the chemical constituents and nematicidal activity of the essential oil of $V$. amurensis roots and its selected major constituents against the cereal cyst nematodes.

\section{EXPERIMENTAL}

\section{Plant collection and identification}

The roots and rhizomes of $V$. amurensis $(10 \mathrm{~kg})$ were from the Great Xing'an Mountains area (Heilongjiang province, China) $\left(50.42^{\circ} \mathrm{N}\right.$ and $124.12^{\circ} \mathrm{E}$ ) in August 2014 and identified by $\mathrm{Dr}$ QR Liu (College of Life Sciences, Beijing Normal University, Beijing 100875, China). A voucher specimen (no. 20140807) was deposited at the herbarium of Institute of Genetics and Physiology, Hebei Academy of Agricultural and Forestry Sciences, Shijiazhuang, China.

\section{Extraction of essential oils}

The sample was cut into small pieces and subjected to hydro distillation using a Clevengertype apparatus for $6 \mathrm{~h}$. Anhydrous $\mathrm{Na}_{2} \mathrm{SO}_{4}$ was used to remove water after extraction. The essential oil was stored in airtight containers in a refrigerator at $4{ }^{\circ} \mathrm{C}$ for subsequent experiments.

\section{Analysis of the essential oils}

Gas chromatography was performed using Hewlett-Packard 5890 gas chromatograph equipped with a flame ionization detector and fused silica capillary column HP-5MS (5\% diphenyl and $95 \%$ dimethylpolysyloxane, $30 \mathrm{~m} \times$ $0.25 \mathrm{~mm}, 0.25 \mu \mathrm{m}$ film thickness), at a flow rate of $1 \mathrm{~mL} \mathrm{~min}^{-1}$. Temperature was programmed from 60 to $280{ }^{\circ} \mathrm{C}$ (at a rate of $20{ }^{\circ} \mathrm{C} \mathrm{min}{ }^{-1}$ ); injector and detector temperatures were 270 and $300{ }^{\circ} \mathrm{C}$, respectively. The components of the essential oils were separated and identified by gas chromatography-mass spectrometry (GCMS) using Agilent $6890 \mathrm{~N}$ gas chromatography coupled to Agilent $5973 \mathrm{~N}$ mass selective detector. The system was equipped with a flame ionization detector and capillary column with HP$5 \mathrm{MS}(30 \mathrm{~m} \times 0.25 \mathrm{~mm} \times 0.25 \mu \mathrm{m})$. GC settings were as follows: the initial oven temperature was held at $60{ }^{\circ} \mathrm{C}$ for $1 \mathrm{~min}$ and ramped at $10{ }^{\circ} \mathrm{C}$ $\min ^{-1}$ to $280^{\circ} \mathrm{C}$ and held there for $15 \mathrm{~min}$. The injector temperature was maintained at $270{ }^{\circ} \mathrm{C}$. The samples $(1 \mu \mathrm{L}$, diluted to 100:1 with acetone) were injected, with a split ratio of 1:10. The carrier gas was helium at a flow rate of 1.0 $\mathrm{mL} \mathrm{min}^{-1}$. Spectra were obtained over the scan range 20 to $550 \mathrm{~m} / \mathrm{z}$ at 2 scans $\mathrm{s}^{-1}$. Most constituents were identified by gas chromatography-mass spectrometry by comparison of their retention indices with those published in the literature or with those of authentic compounds available in our laboratories. The retention indices were determined in relation to a homologous series of n-alkanes (C8-C24) under the same operating conditions. Further identification was made by comparison of their mass spectra with those stored in NIST 05 and Wiley 275 libraries or with mass spectra from literature [19]. Relative percentages of the oil components were calculated based on GC peak areas without using correction factors.

\section{Chemicals}

Bornyl acetate, caryophyllene, isovaleric acid, 3methylvaleric acid and patchoulol were purchased from Aladdin-Reagent Company (Shanghai, China). Fosthiazate was purchased from National Center of Pesticide Standards (8 Shenliao West Road, Tiexi District, Shenyang 110021, China) and used as positive control.

\section{Nematodes}

Cysts of $H$. avenae were extracted from rhizosphere soil of wheat roots collected in Zhengzhou city $\left(34.44^{\circ} \mathrm{N}\right.$ and $\left.112.56^{\circ} \mathrm{E}\right)$, Henan Province, China. Cyst masses were stored at 4 ${ }^{\circ} \mathrm{C}$ for a month firstly and were maintained on wet filter paper in Petri dishes at $15^{\circ} \mathrm{C}$ for $3-7$ days for the juvenile eclosion. Only freshly hatched second stage juveniles $\left(J_{2}\right)$ were used in the experiments. 


\section{Nematicidal bioassay}

Range - finding studies were run to determine the appropriate testing concentrations. A serial dilution of the essential oil (six concentrations, 50 - $1,600 \mu \mathrm{g} / \mathrm{mL}$ ) was prepared in $\mathrm{H}_{2} \mathrm{O}$ solution. Dimethyl sulphoxide (DMSO) was used to firstly dissolve the essential oil and the final concentration of DMSO was $0.2 \%$. Aliquots of $\mathrm{H}_{2} \mathrm{O}(20 \mu \mathrm{L})$ containing ca. 100 juveniles (J2) were transferred to vials containing $980 \mu \mathrm{L}$ of the solution containing the essential oil. The vials were kept on a 100-block box and the box was put into an incubator at $20{ }^{\circ} \mathrm{C}$. The nematodes were observed at $48 \mathrm{~h}$. The nematodes were considered dead if the nematodes did not move and were stiff after addition of 1 - 2 drops of $1 \%$ $\mathrm{NaOH}$ solution. Six repetitions for each treatment were performed using $\mathrm{H}_{2} \mathrm{O}$ and a $0.2 \%$ DMSO in $\mathrm{H}_{2} \mathrm{O}$ solution as a control. The experiments were repeated three times.

\section{Statistical analysis}

The results from all replicates were subjected to Probit analysis using PriProbit Program V1.6.3 to determine $L C_{50}$ values and their $95 \%$ confidence intervals [20]. Samples for which the $95 \%$ fiducial limits did not overlap were considered to be significantly different.

\section{RESULTS}

The essential oil of $V$. amurensis roots and rhizomes was yellow with a yield of $0.21 \%(\mathrm{v} / \mathrm{w})$ and density of $0.91 \mathrm{~g} / \mathrm{mL}$. A total of 33 components of the essential oil were identified accounting for $98.2 \%$ of the total oil.

The major compounds in the essential oil were bornyl acetate (12.5), patchoulol (11.6\%), caryophyllene (8.2\%), 3-methylvaleric acid (7.3 $\%)$ and isovaleric acid (6.5 \%) (Table 1). Sesquiterpenoids represent 19 of 33 compounds, corresponding to $52.3 \%$ of the whole oil while 13 of the 33 constituents were monoterpenoids ( $30.5 \%$ of the whole essential oil) (Table 1).

The essential oil of $V$. amurensis roots and rhizomes exhibited nematicidal activity against $H$. avenae with a $\mathrm{LC}_{50}$ value of $311.6 \mu \mathrm{g} / \mathrm{mL}$ (Table 2). Among 5 selected major constituents, isovaleric acid and 3-methylvaleric acid possessed activity against $H$. avenae with $\mathrm{LC}_{50}$ values of $213.2 \mu \mathrm{g} / \mathrm{mL}$ and $683.6 \mu \mathrm{g} / \mathrm{ml}$, respectively (Table 2) while the other three constituents did not show any nematicidal activity against the cereal cyst nematodes in the current tested concentrations.

\section{DISCUSSION}

The main constituents of the essential oil of $V$. amurensis roots were bornyl acetate, patchoulol, caryophyllene, 3-methylvaleric acid and isovaleric acid. Its chemical composition is quite different from that collected from different populations and different collecting time. For example, the sample essential oil of $V$. amurensis collecting in July in Maoer mountain, Heilongjiang province mainly contained isobornyl acetate $(27.6 \%)$, valeranone $(7.5 \%)$, butylated hydroxytoluene $(7.2 \%)$, a-terpinene $(5.6 \%)$ and 9-cedranone $(5.5 \%)$ while isobornyl acetate $(12.3 \%)$ a-terpinyl acetate (11.6\%), butylated hydroxytoluene $(8.8 \%)$, valeranone $(6.8 \%) \quad \alpha-$ curcumene $(4.3 \%)$, and borneol $(4.2 \%)$ were the major components found in the essential oil of $V$. amurensis roots harvested in September [16].

However, the main compounds in the essential oil of $V$. amurensis roots collected from Huma country, Heilongjiang province, China were caryophyllene (28.04\%), 1,2-diethenyl-4-(1methylethenyl)-cyclohexane (19.83\%) and bornyl acetate (12.08 \%) [17]. The above results suggest that great variations in chemical composition of essential oil of $V$. amurensis roots expected due to harvest time and local, climatic and seasonal factors as well as storage duration of medicinal herbs.

Standardization of essential oil is needed before $V$. amurensis essential oil being commercial because chemical composition of the essential oil of $V$. amurensis varies greatly with plant population and depends on time and place of collection.

The essential oil of $V$. amurensis roots exhibited nematicidal toxicity against the cereal cyst nematodes, $H$. avenae. However, compared with the positive control (fosthiazatete, $\mathrm{LC}_{50}=84.7$ $\mu \mathrm{g} / \mathrm{mL}$ ), $V$. amurensis essential oil showed 4 times less toxic to the cereal cyst nematodes.

Among the five major constituents, isovaleric acid exhibited stronger nematicidal toxicity against $H$. avenae than the crude essential oil and 3-methylvaleric showed less toxicity to cereal cyst nematodes. It is suggested that nematicidal activity of the essential oil maybe attributed to isovaleric acid. 
Table 1: Main compounds of the essential oil of Valeriana amurensis roots

\begin{tabular}{|c|c|c|c|}
\hline Peak no. & Compound & Retention index & (\%) \\
\hline & Monoterpenoids & & 30.5 \\
\hline 1 & $\alpha$-Pinene & 931 & 0.9 \\
\hline 2 & Camphene & 945 & 3.1 \\
\hline 3 & $\beta$-Pinene & 981 & 0.7 \\
\hline 4 & $\beta$-Myrcene & 991 & 1.4 \\
\hline 5 & Limonene & 1029 & 2.6 \\
\hline 6 & 1,8-Cineole & 1031 & 0.6 \\
\hline 7 & Linalool & 1094 & 2.8 \\
\hline 8 & Camphor & 1143 & 0.2 \\
\hline 9 & Borneol & 1174 & 1.9 \\
\hline 10 & a-Terpineol & 1188 & 0.7 \\
\hline 11 & Methyl thymol ether & 1228 & 1.6 \\
\hline 12 & Bornyl acetate & 1287 & 12.5 \\
\hline \multirow[t]{2}{*}{13} & Myrtenyl acetate & 1328 & 1.5 \\
\hline & Sesquiterpenoids & & 53.2 \\
\hline 14 & Copaene & 1375 & 0.6 \\
\hline 15 & $\beta$-Patchoulene & 1382 & 2.3 \\
\hline 16 & $\beta$-Elemene & 1392 & 1.9 \\
\hline 17 & a-Gurjunene & 1406 & 3.5 \\
\hline 18 & Caryophyllene & 1420 & 8.2 \\
\hline 19 & Calarene & 1433 & 3.2 \\
\hline 20 & a-Guaiene & 1437 & 2.7 \\
\hline 21 & a-Caryophyllene & 1449 & 1.1 \\
\hline 21 & Alloaromadendrene & 1462 & 0.3 \\
\hline 22 & $\beta$-Selinene & 1482 & 1.6 \\
\hline 23 & Germacrene D & 1486 & 0.8 \\
\hline 24 & $\delta$-Cadinene & 1525 & 0.2 \\
\hline 25 & Germacrene B & 1552 & 0.6 \\
\hline 26 & Spathulenol & 1574 & 3.3 \\
\hline 27 & Caryophyllene oxide & 1578 & 3.7 \\
\hline 25 & T-Cadinol & 1642 & 0.9 \\
\hline 26 & $\beta$-Eudesmol & 1648 & 0.2 \\
\hline 27 & a-Cadinol & 1655 & 2.8 \\
\hline 28 & Patchoulol & 1660 & 11.6 \\
\hline 29 & Valeranone & 1679 & 3.7 \\
\hline 30 & Isovaleric acid & 875 & 6.5 \\
\hline 31 & 3-Methylvaleric acid & 902 & 7.3 \\
\hline 32 & Valeric acid & 912 & 0.5 \\
\hline \multirow[t]{3}{*}{33} & Eugenol & 1356 & 0.3 \\
\hline & Others & & 14.6 \\
\hline & \multicolumn{2}{|l|}{ Total identified } & 98.3 \\
\hline
\end{tabular}

${ }^{\star} R I$, retention index as determined on a HP-5MS column using the homologous series of $n$-hydrocarbons

Table 2: Nematicidal toxicity of Valeriana amurensis essential oil and its major constituents against Heterodera avenae

\begin{tabular}{lccccc}
\hline Treatment & $\begin{array}{c}\text { Concentration } \\
(\mu \mathrm{g} / \mathbf{m L})\end{array}$ & $\begin{array}{c}\mathbf{L C}_{50} \\
(\mu \mathrm{g} / \mathbf{m L})\end{array}$ & $\begin{array}{c}\text { 95\% Fiducial } \\
\text { limits }\end{array}$ & $\begin{array}{c}\text { Slope } \pm \\
\text { SD }\end{array}$ & $\begin{array}{c}\text { Chi-square } \\
\text { value }\end{array}$ \\
\hline Essential oil & $25-1600$ & 311.6 & $284.4-339.1$ & $3.3 \pm 0.2$ & 11.4 \\
Bornyl acetate & $25-1600$ & $>1600$ & - & - & - \\
Caryophyllene & $25-1600$ & $>1600$ & - & - & - \\
Isovaleric acid & $25-1600$ & 213.2 & $192.5-234.6$ & $3.8 \pm 0.2$ & 12.8 \\
3-Methylvaleric acid & $25-1600$ & 683.8 & $618.3-731.7$ & $3.6 \pm 0.3$ & 11.9 \\
Patchoulol & $25-1600$ & $>1600$ & - & - & - \\
Fosthiazate & $10-640$ & 84.7 & $77.8-91.3$ & $2.3 \pm 0.2$ & 8.5 \\
\hline
\end{tabular}


In the previous report, isovaleric acid and 3methylvaleric acid exhibited contact and fumigant toxicities against the booklice, Liposcelis bostrychophila [22]. However, this is the first time to report the nematicidal activity of isovaleric acid and 3-methylvaleric acid. However, considering the currently used nematicides are synthetic nematicides, nematicidal activity of the essential oil of $V$. amurensis and its two major components, isovaleric acid and 3-methylvaleric acid is quite promising and has some promise as possible natural nematicides for the control of the cereal cyst nematodes. However, to develop a practical application for the essential oil and its major constituents as novel nematicides, further research into the safety of the essential oil and its constituents in humans is needed. Additional studies on the development of formulations are also necessary to improve efficacy and stability as well as to reduce cost.

\section{CONCLUSION}

The essential oil of $V$. amurensis roots and its two major constituents demonstrate some toxicity against cereal cyst nematodes but need to be further evaluated for safety in humans and to enhance their activity.

\section{ACKNOWLEDGEMENT}

This work was funded by Ministry of Agriculture Scientific Research Special Public Welfare Industry (no. 201503114) and Talents Introduction Project of Hebei Province Finance (no. F15E 0010). The authors thank Dr QR Liu of the College of Life Sciences, Beijing Normal University, Beijing, China for the identification of the investigated plant.

\section{REFERENCES}

1. Chitwood DJ. Phytochemical based strategies for nematode control. Annu Rev Phytopathol 2002; 40: 221-249.

2. Bai $C Q$, Liu ZL, Liu QZ. Nematicidal constituents from the essential oil of Chenopodium ambrosioides aerial parts. E-J Chem 2011; 8(S1): 143-148.

3. Du SS, Zhang HM, Bai CQ, Wang CF, Liu QZ, Liu ZL, Wang $Y Y$, Deng $Z W$. Nematocidal flavone-Cglycosides against the root-knot nematodes (Meloidogyne incognita) from Arisaema erubescens tubers. Molecules 2011; 16: 5079-5086.

4. Li HQ, Liu QZ, Liu ZL, Du SS, Deng ZW Chemical composition and nematicidal activity of essential oil of Agastache rugosa against Meloidogyne incognita. Molecules 2013; 18(4): 4170-4180.
5. Liu QZ, Li HQ, Liu ZL. Nematicidal constituents from the ethanol extract of Evodia rutaecarpa Hort unripe fruits. J Chem 2013; doi:10.1155/2013/939215

6. Bai PH, Bai CQ, LiU QZ, Du SS, Liu ZL. Nematicidal activity of the essential oil of Rhododendron anthopogonoides aerial parts and its constituent compounds against Meloidogyne incognita. Z Naturf 2013 68C: 307-312.

7. Ntalli NG, Ferrari F, Giannakou I, Menkissoglu-Spiroudi $U$. Phytochemistry and nematicidal activity of the essential oils from 8 Greek Lamiaceae aromatic plants and 13 terpene components. J Agric Food Chem 2010; 58: 7856-7863.

8. Zhang DX, Hartley TG, Mabberley DJ. Flora of China. 2003.

http://www.efloras.org/florataxon.aspx?flora_id=2\&tax on_id=200022550

9. Wang $Q H$, Wang $C F$, Zuo YM, Wang ZB, Yang $B Y$, Kuang $H X$. Compounds from the roots and rhizomes of Valeriana amurensis protect against neurotoxicity in PC12 cells. Molecules 2012; 17: 15013-15021.

10. Houghton PJ. The biological activity of valerian and related plants. J Ethnopharmacol 1988; 22: 121-142.

11. Zuo YM, Zhang ZL, Wang QH, Xie N, Kuang $H X$. Effects of Valeriana amurensis on the expressions of $\beta-A P P$, A 1-40 and Caspase-3 in Alzheimer's disease model rat's brain. J Chin Med Mater 2010; 33: 233-236.

12. Wang $Q H$, Wang CF, Shu ZP, Chan K, Huang SM, Li Y, Xiao $Y$, Wu LH, Kuang $H X$, Sun XB. Valeriana amurensis improves Amyloid-beta 1-42 induced cognitive deficit by enhancing cerebral cholinergic function and protecting the brain neurons from apoptosis in mice. J Ethnopharmacol 2014; 153: 318325.

13. Wu JK, Wang GS, Du XW, Song N, Zou ZM, Chen JS, Zhang $Y$, Li TL, Wang $X J$, Kuang $H X$. A caryophyllane-type sesquiterpene, caryophyllenol $A$ from Valeriana amurensis. Fitoterapia 2014; 96: 1824.

14. Wang CF, Xiao $Y$, Yang $B Y$, Wang $Z B, W u L H$, Su $X L$, Brantner $A$, Kuang $H X$, Wang $Q H$. Isolation and screened neuroprotective active constituents from the roots and rhizomes of Valeriana amurensis. Fitoterapia 2014; 96: 48-55.

15. Cui L, Wang ZY, Zhou XH. Volatile constituents in the roots and rhizomes oils of Valeriana amurensis. $J$ Essent Oil-Bearing Plant 2010; 13: 130-134.

16. Du XW, Sun H, Wu JK. Extraction methods of essential oils in Valeriana amurensis and study of its chemical constituents. Chin Tradit Herb Drug 2008; 39: 32-34.

17. Wu JK, Huo JH, Du XW. Pharmacological effects of volatile oil of Valeriana amurensis on CNS. J Chin Med Mater 2007; 30: 977-980.

18. Li JL, Yang J, Zhang H, Cui PW, Li ZH. Extraction and analysis of essential oil from Valeriana amurensis. $J$ Chin Cereal Oil Assoc 2010; 25: 52-56.

19. Adams RP. Identification of Essential Oil Components by Gas Chromatograph/Mass Spectrometry. 4th ed. 


\section{Li et al}

Allured Publishing Corpoartion, Carol Stream, USA, 2007.

20. Sakuma M. Probit analysis of preference data. Appl Entomol Zool 1998; 33: 339-347.
21. Liu XC, Zhou L, Liu ZL. Identification of insecticidal constituents from the essential oil of Valeriana jatamansi Jones against Liposcelis bostrychophila Badonnel. J Chem 2014; http://dx.doi.org/10.1155/ 2013/853912 